\title{
Integrated Vacuum Stripping and Adsorption for the Efficient Recovery of (Biobased) 2-Butanol
}

\author{
Joana P. C. Pereira, ${ }^{\dagger}$ (๑ Wouter Overbeek, ${ }^{\dagger}$ Noelia Gudiño-Reyes, ${ }^{\dagger}$ Eduardo Andrés-García, ${ }^{\dagger}$ \\ Freek Kapteijn, ${ }^{\ddagger \odot}$ Luuk A. M. van der Wielen, ${ }^{\dagger}$ and Adrie J. J. Straathof ${ }^{*}, \oplus$
}

${ }^{\dagger}$ Department of Biotechnology and ${ }^{\ddagger}$ Catalysis Engineering, Chemical Engineering Department, Delft University of Technology, van der Maasweg 9, $2629 \mathrm{HZ}$ Delft, The Netherlands

Supporting Information

ABSTRACT: Biobased 2-butanol offers high potential as biofuel, but its toxicity toward microbial hosts calls for efficient techniques to alleviate product inhibition in fermentation processes. Aiming at the selective recovery of 2-butanol, the feasibility of a process combining in situ vacuum stripping followed by vapor adsorption has been assessed using mimicked fermentation media. The experimental vacuum stripping of model solutions and corn stover hydrolysate closely aligned with mass transfer model predictions. However, the presence of lignocellulosic impurities affected 2-butanol recovery yields resulting

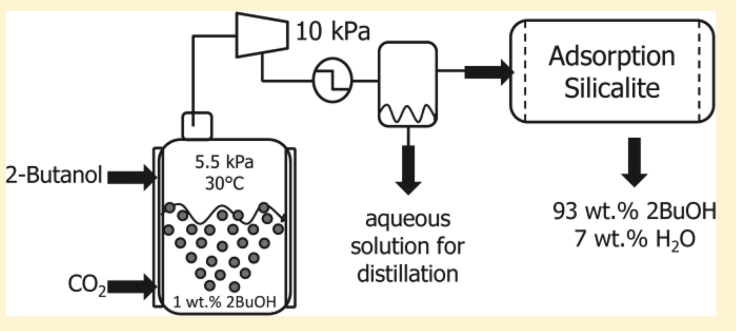
from vapor condensation, which decreased from $96 \mathrm{wt} \%$ in model solutions to $40 \mathrm{wt} \%$ using hydrolysate. For the selective recovery of 2-butanol from a vapor mixture enriched in water and carbon dioxide, silicalite materials were the most efficient, particularly at low alcohol partial pressures. Integrating in situ vacuum stripping with vapor adsorption using HiSiv3000 proved useful to effectively concentrate 2-butanol above its azeotropic composition ( $>68 \mathrm{wt} \%$ ), facilitating further product purification.

\section{INTRODUCTION}

The use of renewable feedstocks for the production of biofuels and commodity chemicals enables carbon recycling, as opposed to the use of petrochemical feedstocks, therefore reducing the carbon footprint in the industrial sector. When competitively produced, biobased products can effectively reach the markets, similar to what happened with bioethanol and biobutanol, ${ }^{1}$ promoting a sustainable bioeconomy.

Among the butanol isomers that can be produced from biomass, 2-butanol appears as a promising biofuel, mainly due to its higher octane and motor numbers and lower boiling temperature. 2-Butanol is also a crucial intermediate in biobased production of methyl methacrylate, as recently suggested. ${ }^{2}$ Therefore, it has attracted the attention of several researchers in the past decade. ${ }^{3-7}$ Biobased 2-butanol is known to be naturally produced by Lactobacillus strains in the winemaking industry, as a result of the dehydration of 2,3butanediol into butanone and its following reduction into 2butanol. ${ }^{8}$ Aiming at competitive production, Ghiaci ${ }^{5}$ attempted to produce 2-butanol using engineered Saccharomyces cerevisiae strains, but due to the low activity of the adenosylcobalamindependent diol dehydratase, only a concentration of $4 \mathrm{mg} / \mathrm{L}$ was achieved. Using a different approach, $\mathrm{Chen}^{6}$ extended the natural meso-2,3-butanediol pathway in Klebsiella pneumoniae and achieved $1.03 \mathrm{~g} / \mathrm{L}$ 2-butanol from glucose, with a productivity of ca. $0.03 \mathrm{~g} /(\mathrm{L} \mathrm{h})$. While this volumetric productivity is still far from industrial targets, previously estimated as $2 \mathrm{~g} /(\mathrm{L} \mathrm{h}),{ }^{9}$ the studies show that the enzyme constructs are functional, and competitive strains for industrial applications might be engineered within few years, as happened with other fermentation products. ${ }^{10}$ However, 2butanol severely inhibits microbial growth when product concentrations reach $10 \mathrm{~g} / \mathrm{L}^{11}$. Metabolic engineering can be used to enhance the microbial tolerance to biobased chemicals, but it is still challenging to increase tolerance levels up to economically feasible product titers. ${ }^{12}$ Therefore, in situ product recovery (ISPR) techniques are widely used to alleviate product inhibition, enhance volumetric productivities, and overcome the downstream processing costs resulting from low product titers in fermentation. ${ }^{13}$

Among the different ISPR options, reviewed elsewhere, ${ }^{13-15}$ vacuum fermentation is a promising vapor-based technology that exploits the relative volatility of the fermentation products, facilitating their separation from the cells and nonvolatile lignocellulosic impurities. This technology is particularly efficient in ethanol fermentation given its low boiling point, ${ }^{16}$ but its technical feasibility has also been demonstrated for 1butanol in acetone-butanol-ethanol (ABE) fermentation, ${ }^{17}$ depicting higher selectivity and faster removal rates than those with gas stripping. The recovery of 1-butanol from the stripped vapor is typically performed by condensation, and the heterogeneous azeotropic mixture formed in 1-butanol/water systems facilitates further product purification by means of conventional decantation and distillation. ${ }^{18-20}$ The relative volatility of 2 -butanol at infinite dilution, however, is 2.2 -fold

Received: July 5, 2018

Revised: November 29, 2018

Accepted: December 12, 2018

Published: December 12, 2018 
lower than that of 1-butanol and 1.7-fold lower than that of isobutanol, which might hinder the selective recovery of this alcohol. Additionally, 2-butanol/water systems form a homogeneous azeotrope, which cannot be separated using conventional distillation methods. ${ }^{7}$ Although 2-butanol can be concentrated up to ca. $62 \mathrm{wt} \%$ by phase separation in a decanter, this composition is still below the azeotrope (ca. 68 wt $\%$ 2-butanol). As a result, further product purification by distillation is impracticable. Therefore, a technically feasible alternative is required to recover 2-butanol from the stripped vapor and further concentrate the alcohol above its azeotropic composition.

Adsorption-based technologies have often proved to be advantageous over other recovery technologies regarding energy requirements. ${ }^{15,18}$ Combined with vacuum stripping, adsorption from fermentation vapor would avoid typical liquidphase adsorption bottlenecks such as nutrient/substrate removal and adsorbent fouling. ${ }^{21,22}$ To selectively remove alcohols from dilute aqueous solutions, adsorbents with higher affinity toward nonpolar compounds are preferred. ${ }^{23}$ For instance, aluminum-free silicalite and zeolites with a high silica-aluminum $\left(\mathrm{SiO}_{2} / \mathrm{Al}_{2} \mathrm{O}_{3}\right)$ ratio exhibited high alcohol selectivity and adsorption capacities and proved to be robust when handling regenerative temperature swing cycles. ${ }^{24-26}$ Also, activated carbons were effective for the selective adsorption of alcohols from model solutions; $;^{27,28}$ and polymeric resins such as Sepabeads 207, based on a poly(styrenedivinylbenzene) matrix that enhances hydrophobicity, proved to be an effective option for ethanol recovery, ${ }^{29,30}$ yet significantly more expensive than zeolite, silicalite, or activated carbon materials.

The adsorptive behavior of water and 1-butanol onto materials such as silicalite, ${ }^{31}$ zeolites, $^{32,33}$ and activated carbons ${ }^{23,34}$ has been reported in the literature, as has the adsorptive behavior of $\mathrm{CO}_{2}$ onto zeolites and activated carbons. ${ }^{35}$ However, studies focusing on the selective alcohol adsorption from stripped fermentation vapor, enriched in water and $\mathrm{CO}_{2}$, are scarce. ${ }^{28,31}$

In the present work, we investigate the feasibility of in situ vacuum stripping for the selective removal of 2-butanol from model solutions and corn stover hydrolysate. Aiming at product concentrations above the azeotropic composition of 2-butanol/water systems, four commercially available adsorbents, namely, a zeolite, a silicalite, an activated carbon, and a polymeric resin, will be screened for the selective recovery of the alcohol from stripped vapor, enriched in water and carbon dioxide. A mathematical model, initially developed by Löser, ${ }^{36}$ will be adapted to describe the vacuum stripping process. The efficiency of product recovery by condensation, as well as the achievable 2-butanol concentration in the condensate, will also be assessed. Pure component isotherm data will be used to model the multicomponent adsorption in a fixed bed column, and identify the most promising adsorbent for this process. To the best of the authors' knowledge, the technical feasibility of vacuum stripping using lignocellulosic hydrolysates has not yet been assessed. Additionally, this is the first study on the experimental feasibility of in situ 2-butanol recovery, using vacuum stripping and adsorption technologies, and the data provided can be used for the conceptual design of a large-scale integrated process.

\section{MATERIALS AND METHODS}

2.1. Materials. Analytical-grade 2-butanol (99.5 wt \%) was supplied by Sigma-Aldrich. Glucose (99.9 wt \%) was obtained from J. T. Baker. Gaseous $\mathrm{CO}_{2}$ (>99.99 wt \%) was supplied by Air Liquide. Deionized water was used to prepare the model solutions.

Corn stover hydrolysate, containing ca. 20.5 wt \% solids, 10.5 wt \% sugars, 0.5 wt $\%$ acetic acid, 0.07 wt $\%$ formic acid, 0.04 wt \% 5-hydroxymethylfurfural, and 0.01 wt \% furfural, was kindly provided by DSM (Delft, The Netherlands).

Four commercial adsorbents were tested for selective product recovery: powdered ZSM-5 zeolite CBV28014 $\left(\mathrm{SiO}_{2} / \mathrm{Al}_{2} \mathrm{O}_{3}=280\right.$, Zeolyst International, USA), pelletized silicalite HiSiv3000 $\left(\mathrm{SiO}_{2} / \mathrm{Al}_{2} \mathrm{O}_{3}=218\right.$, UOP Products, Belgium), activated carbon F-400 (Chemviron Carbon, Belgium), and resin Sepabeads SP207 (Resindion S.R.L., Italy). These adsorbents have been selected based on reported adsorption capacities for alcohols (1-butanol and ethanol) and water. $^{23,25,27,29-31,37}$ These values are depicted in Table 1, along with some physical properties of the adsorbents.

Table 1. Properties of the Selected Adsorbents According to the Manufacturers ${ }^{a}$

\begin{tabular}{|c|c|c|c|c|}
\hline adsorbents & $\begin{array}{l}\text { surface area } \\
\left(\mathrm{m}^{2} / \mathrm{g}\right)\end{array}$ & $\begin{array}{l}\text { pore volume } \\
\left(\mathrm{cm}^{3} / \mathrm{g}\right)\end{array}$ & $\frac{q_{\max , \mathrm{ROH}}}{(\mathrm{g} / \mathrm{g})}$ & $\begin{array}{c}q_{\max , \mathrm{H}_{2} \mathrm{O}} \\
(\mathrm{g} / \mathrm{g})\end{array}$ \\
\hline $\begin{array}{l}\text { zeolite } \\
\text { powder }\end{array}$ & 400 & 0.19 & $0.133^{31}$ & $0.061^{25}$ \\
\hline $\begin{array}{l}\text { silicalite } \\
\text { pellets }\end{array}$ & 282 & 0.15 & $0.100^{27}$ & $0.051^{37}$ \\
\hline $\begin{array}{c}\text { activated } \\
\text { carbon }\end{array}$ & 1090 & 0.43 & $0.206^{27}$ & $0.396^{38}$ \\
\hline resin & 600 & 1.10 & $1.250^{29}$ & $0.920^{29}$ \\
\hline
\end{tabular}

2.2. Vacuum Stripping Studies. Vacuum-stripping experiments under anaerobic conditions were performed at $30.0 \pm 0.5{ }^{\circ} \mathrm{C}$ in a $20 \mathrm{~L}$ stainless steel reactor (Applikon BIO BENCH 20, The Netherlands), fitted with typical sensors for $\mathrm{pH}$, temperature, and pressure (Figure 1). The working

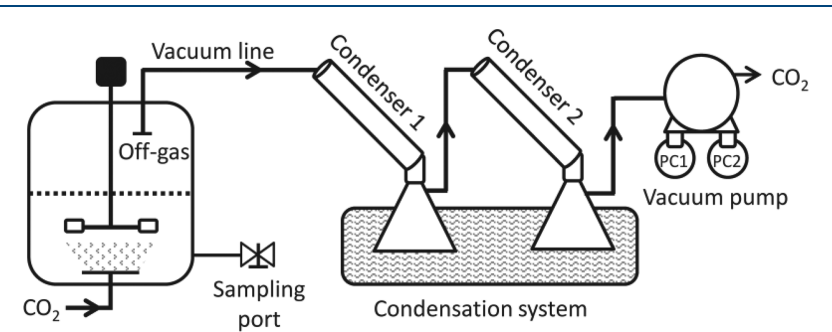

Figure 1. Experimental setup for in situ 2-butanol recovery by vacuum stripping

volume was $10 \mathrm{~L}$. To mimic microbial production, $\mathrm{CO}_{2}$ was sparged at a rate of ca. $0.054 \mathrm{~mol} /(\mathrm{L} \mathrm{h})$. This rate was calculated stoichiometrically, assuming a hypothetical 2butanol volumetric productivity of $0.027 \mathrm{~mol} /(\mathrm{L} \mathrm{h}) .^{7}$ This rate translated into a $\mathrm{CO}_{2}$ gas flow of ca. $13 \pm 3 \mathrm{~L} / \mathrm{h}$, which was measured using a mass flow controller. The off-gas port of the reactor was attached to the condensation system, which comprised a series of two Liebig-type condensers $(40 \mathrm{~cm})$, coupled to Erlenmeyer flasks $(250 \mathrm{~mL})$ submerged at $-7^{\circ} \mathrm{C}$ in the cryostat (ECO RE 620, Lauda). A vacuum pump (KNF 
Neuberger, SC920), positioned downstream of the condensation system, controlled the overall pressure at $5.5 \pm 0.5 \mathrm{kPa}$. The pump was equipped with two additional condensers, PC1 and $\mathrm{PC} 2$, both at room temperature, but at different pressures: $\mathrm{PC} 1$ was at $5.5 \pm 0.5 \mathrm{kPa}$, while PC2 was at room pressure (vapor compression ratio ca. 18).

Two series of experiments were performed, viz., vacuum stripping of model solutions containing 2-butanol and glucose (ca. $45 \mathrm{~g} / \mathrm{L}$ ) and vacuum stripping of 2-butanol-containing corn stover hydrolysate. The vacuum pressure, along with the gaseous $\mathrm{CO}_{2}$ flow, provided sufficient turbulence in the model solutions containing 2-butanol, and stirring was not applied. The corn stover hydrolysate, however, was significantly denser than the model solutions, and stirring (150 rpm) was applied to facilitate mass transfer and prevent solid sedimentation.

The system was monitored using the MFCS/win 3.0 software (Sartorius), and aqueous samples $(0.5 \mathrm{~mL})$ were collected hourly, using an external sampling loop, which allowed sample collection without hampering the vacuum pressure. The samples of hydrolysate were first centrifuged at $13000 \mathrm{~g}$ for $1 \mathrm{~min}$, after which the supernatant was collected. Upon termination of the experiments, the volume and mass of the condensates, as well as the remaining solution in the reactor, were determined. All the samples were stored at -20.0 ${ }^{\circ} \mathrm{C}$ until 2-butanol quantification.

A mathematical model, describing the vacuum stripping of 2-butanol, has been adapted from the batch-process model proposed by Urit. ${ }^{39} i$ stands for the specific components 2 butanol, water, and $\mathrm{CO}_{2}$. The initial concentrations of $i$ in the liquid and vapor phases, $C_{i, \mathrm{~L}}$ and $C_{i, \mathrm{G}}$, respectively, have been used as model input parameters and further translated into the respective molar fractions $x_{i}$ and $y_{i}$ (for more information, see the "Nomenclature" section):

$$
\begin{aligned}
& C_{i, \mathrm{~L}}=\frac{n_{i, \mathrm{~L}}}{V_{\mathrm{L}}} \\
& C_{i, \mathrm{G}}=\frac{n_{i, \mathrm{G}}}{V_{\text {reactor }}-V_{\mathrm{L}}} \\
& x_{i}=\frac{n_{i, \mathrm{~L}}}{\sum n_{i, \mathrm{~L}}} \\
& y_{i}=\frac{n_{i, \mathrm{G}}}{\sum n_{i, \mathrm{G}}}
\end{aligned}
$$

The concentration of $\mathrm{CO}_{2}$ in the liquid has been determined as total soluble inorganic carbon, $C_{\mathrm{C}_{\mathrm{tot}} \mathrm{L}}$, and subsequently translated into each species of the carbonate buffer system, i.e., dissolved $\mathrm{CO}_{2}$, carbonic acid, bicarbonate, and carbonate, using the mathematical model proposed by Contreras. ${ }^{40}$ The dissolved $\mathrm{CO}_{2}$ is determined according to

$$
C_{\mathrm{C}, \mathrm{L}}=\frac{C_{\mathrm{C}_{\mathrm{tot}} \mathrm{L}} \times C_{\mathrm{H}^{+}, \mathrm{L}}^{2}}{C_{\mathrm{H}^{+}, \mathrm{L}}^{2}+K_{1} C_{\mathrm{H}^{+}, \mathrm{L}}+K_{1} K_{2}}
$$

$K_{1}$ and $K_{2}$ are the known dissociation constants of carbonic acid, ${ }^{41}$ and $C_{\mathrm{H}^{+}, \mathrm{L}}$ stands for the free proton concentration in solution.

The liquid volume, $V_{\mathrm{L}}$, is a time-dependent variable determined according to

$$
V_{\mathrm{L}}=\frac{\sum\left(n_{i, \mathrm{~L}} \times M_{\mathrm{wi}}\right)}{\rho_{\text {mix }}}
$$

The density of aqueous 2-butanol, $\rho_{\text {mix }}$ was determined from its molar composition according to Senanayake. ${ }^{42}$ The experimental density of the corn stover hydrolysate was determined to be $1.08 \mathrm{~kg} / \mathrm{L}$, and its viscosity was estimated to be $0.09 \mathrm{~Pa}$ s, according to Hou. ${ }^{43}$

The material balances for 2-butanol, water, and $\mathrm{CO}_{2}$ in the liquid phase consider their transfer from the liquid to the vapor phase, $\theta_{i}$ :

$$
\frac{\mathrm{d} n_{i, \mathrm{~L}}}{\mathrm{~d} t}=-\theta_{i}
$$

In the vapor phase, the material balances consider the molar inflow of $\mathrm{CO}_{2}\left(F_{\mathrm{CO}_{2} \text {,in }}\right)$, and outflow $\left(F_{\text {out }}\right)$ of each component $i$ :

$$
\frac{\mathrm{d} n_{i, \mathrm{G}}}{\mathrm{d} t}=F_{\mathrm{CO}_{2}, \text { in }}+\theta_{i}-F_{\text {out }} \times y_{i, \text { out }}
$$

The overall pressure in the reactor is determined according to the ideal gas law:

$$
P=\frac{\sum n_{i, \mathrm{G}} \times R \times T}{\left(V_{\text {reactor }}-V_{\mathrm{L}}\right)}
$$

Ideally, to uphold a constant pressure in the reactor, the total amount of moles per volume of vapor phase $\left(\sum n_{i, \mathrm{G}} /\left(V_{\text {reactor }}-\right.\right.$ $\left.V_{\mathrm{L}}\right)$ ) should be constant; therefore, $F_{\text {out }}=F_{\mathrm{CO}_{2} \text {,in }}+\sum \theta_{i}$. In the present case, the vacuum pump was affected by a pumping delay that caused up to $10 \%$ pressure buildup. This constrained the value of $F_{\text {out }}$. As an attempt to mimic this effect, $F_{\text {out }}$ was calibrated as a function of the pressure in the reactor. Considering a constant vapor phase volume in the reactor $\left(V_{\text {reactor }}=20 \mathrm{~L} ; V_{\mathrm{L}}=0 \mathrm{~L}\right), P$ was decreased over measured time steps, starting from room pressure down to $5.5 \mathrm{kPa}$. Using eq 9 , the number of moles stripped per time unit $\left(F_{\text {out }}\right)$ was determined. The experimental values of $F_{\text {out }}$ were then plotted as a function of $P$, and the best fit to this series $\left(F_{\text {out }}=-8 \times\right.$ $\left.10^{-6} P^{3}+1.4 \times 10^{-3} P^{2}+0.2 P-0.8 ; R^{2}=0.99\right)$ was used to estimate $F_{\text {out }}$ in the simulation.

The transfer rate of compounds via the liquid/vapor interface, $\theta_{i}$, is dependent on the mass transfer coefficient, $k_{\mathrm{L}, i} a$, and the amount of moles of $i$ at the liquid interface, $n_{i, \mathrm{~L}}^{*}$ :

$$
\theta_{i}=k_{\mathrm{L}, i} a \times\left(n_{i, \mathrm{~L}}-n_{i, \mathrm{~L}}^{*}\right)
$$

The mass transfer coefficient, $k_{\mathrm{L}, i} a$, was determined for each component by using the experimental $k_{\mathrm{L}, \mathrm{O}_{2}} a$ value and the relationship proposed by Truong and Blackburn. ${ }^{44}$ At the liquid interface, $n_{i, \mathrm{~L}}^{*}$ is related to the partition coefficient, $K_{i}$ :

$$
\begin{aligned}
& n_{i, \mathrm{~L}}^{*}=K_{i} \times y_{i} \times \sum n_{i, \mathrm{~L}} \\
& K_{i}=\frac{x_{i}}{y_{i}}=\frac{P}{\gamma_{i} P_{i}^{\text {sat }}}
\end{aligned}
$$

The modified-UNIFAC model $^{45}$ was used to compute the values of activity coefficients, $\gamma_{i}$, and the temperaturedependent $P_{i}^{\text {sat }}$ value was determined using Antoine's equation. ${ }^{46} \mathrm{CO}_{2}$ transfer via the interface, which depends on its aqueous saturation concentration, was predicted using the Henry coefficient: 


$$
n_{C, \mathrm{~L}}^{*}=y_{i} \times V_{\mathrm{L}} \times \frac{P}{H_{i}}
$$

$H_{i}$ was determined for the operational temperature according to the parameters provided by Green and Perry. ${ }^{47}$

The system of equations described was iteratively solved using Matlab ODE15s, Matlab R2014b (Mathworks), with $t$ as the independent variable. The average relative error, $\delta$, has been used to evaluate the fitting accuracy of the model to the experimental data:

$$
\delta=\frac{100}{n} \sum\left|\frac{C_{i, \exp }-C_{i, \bmod }}{C_{i, \exp }}\right|
$$

2.3. Adsorption Studies. ZSM-5 and HiSiv3000 were calcined for $8 \mathrm{~h}$ at $600{ }^{\circ} \mathrm{C}$. F-400 and the SP207 were dried overnight at 200 and $70^{\circ} \mathrm{C}$, respectively. The adsorbents were stored in an oven at $70{ }^{\circ} \mathrm{C}$ until further use. Immediately before the experiments, the adsorbents were accurately weighed, and out-gassed overnight at $1 \mathrm{kPa}$.

The single-component isotherms were determined at $30{ }^{\circ} \mathrm{C}$. Gas adsorption was performed by volumetric method, using a high-pressure gas adsorption system BELSORP-HP (BEL Japan, INC). with equilibration time of $0.33 \mathrm{~h}$ for each measurement. Vapor adsorption was performed using an Autosorb-1-C volumetric adsorption analyzer (Quantachrome $\mathrm{GmbH} \& \mathrm{Co} . \mathrm{KG}$, Germany). Equilibrium was assumed if the pressure variation in $0.17 \mathrm{~h}$ was $<0.01 \%$. Saturated vapor equilibrium experiments were performed in triplicate under controlled temperature, using sealed, depressurized desiccators, in which a weighed amount of adsorbent was placed in a plate above a flask containing liquid adsorbate. The mass variation of the adsorbent after $168 \mathrm{~h}$ was used to estimate the maximum vapor uptake.

Several equilibrium isotherm models exist, and reviews regarding their application and consistency can be found elsewhere. ${ }^{48}$ In the present work, the Langmuir isotherm, ${ }^{49}$ the Sips isotherm, ${ }^{50}$ and the Brunauer-Emmett-Teller (BET) isotherm ${ }^{51}$ were selected to correlate the single-component adsorption data. The well-known Freundlich isotherm model ${ }^{52}$ depicted significantly higher relative errors for the majority of the cases (data not shown) and was therefore excluded from this study. The Sips isotherm model, shown in eq 15, combines both Langmuir and Freundlich relations to predict heterogeneous adsorption systems via the index of heterogeneity, $a$. At high adsorbate concentration, $a=1$, and a typical Langmuir isotherm is predicted. The BET isotherm (eq 16) is used to describe finite multilayer adsorption systems: First, the parameters $b_{i}$ and $q_{\max , i}$ were determined from the slope and intercept of the line resulting from the linearization of eq 17 , using the low-pressure region of the experimental data $\left(P_{i} \leq\right.$ $0.35)$. These parameters were then used in eq 16, and the average number of adsorption layers $\alpha$ was estimated by curve fitting. ${ }^{51}$ The adsorption parameters in eqs 15 and 16 were estimated by iterative nonlinear minimization of the sum of squared residuals, using Matlab R2014b (Mathworks). The average relative error $\delta$ and the coefficient of determination $R^{2}$ were used to measure the fitting accuracy of the models. ${ }^{48}$ To predict competitive adsorption, the multicomponent Sips isotherm, shown in eq 18 , was used. ${ }^{53}$ For the cases in which Langmuir depicted better fits, Langmuir's parameters were used with $a=1$. Regarding the cases better described by the $\mathrm{BET}$ isotherm, multicomponent adsorption was predicted using the second best fit isotherm model (either Langmuir or Sips).

$$
\begin{aligned}
& q_{\mathrm{eq}, i}=\frac{q_{\mathrm{max}, i}\left(b_{i} P_{i}\right)^{1 / a}}{1+\left(b_{i} P_{i}\right)^{1 / a}} \\
& q_{\mathrm{eq}, i}=\frac{q_{\mathrm{max}, i} b_{i}\left(P_{i} / P_{i}^{\mathrm{sat}}\right)}{1-\left(P_{i} / P_{i}^{\mathrm{sat}}\right)}\left\{\frac{1-(\alpha+1)\left(P_{i} / P_{i}^{\mathrm{sat}}\right)^{\alpha}}{1+\left(b_{i}-1\right)\left(P_{i} / P_{i}^{\mathrm{sat}}\right)}\right. \\
& q_{\mathrm{eq}, i}=\frac{q_{\mathrm{max}, i} b_{i} P_{i}}{\left(P_{i}^{\mathrm{sat}}-P_{i}\right)\left[1+\left(b_{i}-1\right)\left(P_{i} / P_{i}^{\mathrm{sat}}\right)\right]} \\
& q_{\mathrm{eq}, i}=\frac{q_{\mathrm{max}, i} b_{i} P_{i}\left(\sum b_{j} P_{j}\right)^{1 / a-1}}{1+\left(\sum b_{j} P_{j}\right)^{1 / a}}
\end{aligned}
$$$$
q_{\mathrm{eq}, i}=\frac{q_{\mathrm{max}, i} b_{i}\left(P_{i} / P_{i}^{\mathrm{sat}}\right)}{1-\left(P_{i} / P_{i}^{\mathrm{sat}}\right)}\left\{\frac{1-(\alpha+1)\left(P_{i} / P_{i}^{\mathrm{sat}}\right)^{\alpha}+\alpha\left(P_{i} / P_{i}^{\mathrm{sat}}\right)^{\alpha+1}}{1+\left(b_{i}-1\right)\left(P_{i} / P_{i}^{\mathrm{sat}}\right)-b_{i}\left(P_{i} / P_{i}^{\mathrm{sat}}\right)^{\alpha+1}}\right\}
$$

2.4. Integrated Vacuum Stripping and Adsorption. The integration of vacuum stripping and adsorption was evaluated by means of mathematical simulation, using Adsim. The mathematical model previously developed in section 2.2 was used to predict the composition of the vapor stripped from a continuous fermentation at pseudosteady-state, in which 2butanol was produced at a rate of $2 \mathrm{~g} /(\mathrm{L} \mathrm{h})$. A fixed bed column with plug flow was considered for vapor adsorption, assuming isothermal conditions and neglecting radial gradients. The pressure drop in the column was estimated using Ergun's equation. ${ }^{54}$ The mass and heat transfer coefficients were derived from well-known correlations, suggested in the literature. ${ }^{55,56}$ The mass transfer resistances were determined via the lumped linear driving force approximation, ${ }^{57}$ and the ideal gas theory was used to describe the thermodynamic process. The adsorbent requirements were estimated by means of mass balance, assuming fixed bed saturation, considering a production capacity of 101 kton 2-butanol/a. The breakthrough curves were evaluated for different vapor flow velocities, allowing for the loss of 1 wt \% 2-butanol. Therefore, at least 99 wt \% of the stripped 2-butanol was recovered by adsorption in the column.

2.5. Analytical Methods. Aqueous concentrations of 2butanol were determined via GC (InterScience, The Netherlands), using a Zebron ZB-WAX-PLUS column (30 $\mathrm{m} \times 0.32$ $\mathrm{mm} \times 0.50 \mu \mathrm{m})$. 1-Pentanol $(320 \mathrm{mg} / \mathrm{L})$ was used as internal standard. The temperature was $30{ }^{\circ} \mathrm{C}$ for $5 \mathrm{~min}$, followed by a gradient of $20{ }^{\circ} \mathrm{C} / \mathrm{min}$ for $5 \mathrm{~min}$. The temperatures of the injector and FI detector were 200 and $250^{\circ} \mathrm{C}$, respectively.

\section{RESULTS AND DISCUSSION}

3.1. Selective Recovery of 2-Butanol via in Situ Vacuum Stripping and Vapor Condensation. The efficiency of in situ vacuum stripping was analyzed by targeting the selective removal of 2-butanol from model solutions. The effect of other fermentation compounds was evaluated using corn stover hydrolysate. The concentration profiles of 2butanol in the reactor, resulting from the vacuum stripping of model solutions and hydrolysate, are shown in Figure 2. The initial concentration of 2-butanol in the mixtures was within the range expected in fermentations, tolerating a $50 \%$ reduction in the maximum microbial growth rate due to toxicity. ${ }^{11}$ Figure 2 shows that the vacuum stripping process is in agreement with the model predictions for model solutions and hydrolysate, with low average relative errors of $1.6 \pm 0.1 \%$ 


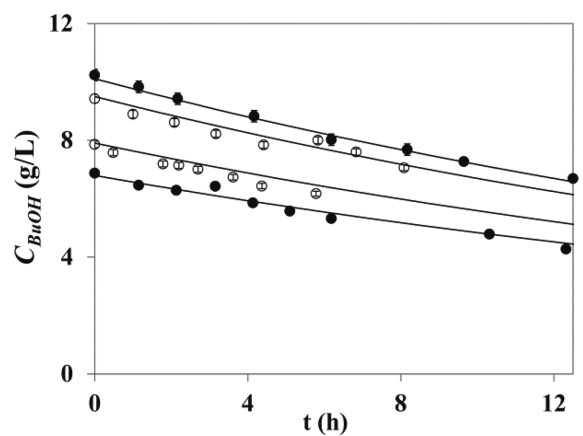

Figure 2. Comparison between experimental (markers) and predicted (lines) concentrations of 2-butanol in the aqueous phase, during the vacuum stripping of model solutions (filled symbols), and hydrolysate (open symbols). $T=30{ }^{\circ} \mathrm{C} ; P=5.5 \mathrm{kPa}$.

and $2.8 \pm 0.2 \%$, respectively. Thus, the model can accurately predict 2-butanol concentration profiles and condensate compositions for a wide range of operational conditions and mixtures. Overall, the stripping rate and the favorable 2butanol removal over other compounds, namely, water, were found to increase with the product concentration in the aqueous mixture, as observed in other studies. ${ }^{58,59}$

The measured mass of 2-butanol stripped from model solutions and hydrolysate, as well as its mole fraction, concentration in the recovered condensates, and stripping selectivity, $S_{\mathrm{BuOH}}=\left[\left(x_{\mathrm{BuOH}, \text { cond }} / x_{\text {wat,cond }}\right) /\left(x_{\mathrm{BuOH}, \text { broth }} /\right.\right.$ $\left.\left.x_{\text {wat,broth }}\right)\right]$, are given in Table 2 . These values were obtained

Table 2. Masses, Mole Fractions, Concentrations, and Selectivities Measured after Vacuum Stripping of Model Solutions at $T=30^{\circ} \mathrm{C}$ and $P=5.5 \mathrm{kPa}$

\begin{tabular}{lll} 
& \multicolumn{1}{c}{ model solution } & \multicolumn{1}{c}{ hydrolysate } \\
$t_{\text {exp }}(\mathrm{h})$ & 12 & 8 \\
$C_{\mathrm{BuOH}, t=0}(\mathrm{~g} / \mathrm{L})$ & $10.2 \pm 0.2$ & $9.4 \pm 0.2$ \\
$m_{\mathrm{BuOH}, \text { strip }}(\mathrm{g})$ & $34 \pm 1$ & $25 \pm 3$ \\
$m_{\mathrm{BuOH}, \text { cond }}(\mathrm{g})$ & $32 \pm 1$ & $10.0 \pm 0.2$ \\
recovery $(\%)$ & $96 \pm 3$ & $40 \pm 5$ \\
$m_{\text {wat,cond }}(\mathrm{g})$ & $178.3 \pm 0.8$ & $111.5 \pm 0.2$ \\
$x_{\mathrm{BuOH}, \text { cond }}(\mathrm{mol} / \mathrm{mol})$ & $(421 \pm 11) \times 10^{-4}$ & $(214 \pm 4) \times 10^{-4}$ \\
$C_{\mathrm{BuOH}, \text { cond }}(\mathrm{g} / \mathrm{L})$ & $147 \pm 4$ & $81 \pm 2$ \\
$S_{\mathrm{BuOH}, \text { cond }}(-)$ & $17.5 \pm 0.5$ & $9.3 \pm 0.2$ \\
$S_{\mathrm{BuOH}, \text { cond }}(-)^{a}$ & $18.4 \pm 0.6$ & $22.9 \pm 2.8$
\end{tabular}

${ }^{a}$ Stripping selectivity considering $100 \%$ product recovery by condensation.

after termination of the experiments. Water was stripped at a constant rate of $1.42 \pm 0.06 \mathrm{~g} /(\mathrm{L} \mathrm{h})$, and $96.6 \pm 0.1 \mathrm{wt} \%$ of the stripped water was collected in Condenser 1 (recall Figure $1)$. Conversely, the higher activity coefficient of 2-butanol $\left(\gamma_{\mathrm{BuOH}} \approx 18.7\right)$ enhanced $\theta_{\mathrm{BuOH}}$, promoting its evaporation along the condensation system. In the pump condenser PC2, the high compression ratio caused 2-butanol to condense at $20^{\circ} \mathrm{C}$. This condenser contained the highest product mass fraction (61 wt \%) and ca. 19 wt \% of the total 2-butanol stripped from the model solutions.

The extent of 2-butanol recovery by condensation decreased drastically to $40 \pm 5 \%$ using hydrolysate mixtures, as opposed to model solutions. As a result, the stripping selectivity was roughly twice as low. Residual amounts of typical hydrolysate compounds, namely, furfural, acetic, and formic acids, among other unidentified compounds, were found in the condensate. The chemical composition of a mixture is known to influence vapor-liquid equilibria, and the addition of ternary species is widely used to facilitate the selective removal of alcohols, by promoting their relative volatility. ${ }^{60,61}$ This effect was minimized in the reactor, due to the dilute concentrations of product and hydrolysate compounds, but their comparatively higher molar fraction in the condensate enhanced $\gamma_{\mathrm{BuOH}}$ and, therefore, 2-butanol evaporation. The composition of the hydrolysate also caused technical issues not observed with model solutions, namely, the obstruction of the sampling device, which led to shorter experimental runs (ca. 5-8 h, as opposed to ca. $12 \mathrm{~h}$ using model solutions).

The predictive model was used to analyze the effect of increasing the driving force for evaporation $\left(F_{\text {out }}\right)$ on 2-butanol concentrations and condensate compositions, by increasing the $\mathrm{CO}_{2}$ flow rate $\left(F_{\mathrm{CO}_{2} \text {,in }}\right)$ in the simulations accordingly. A continuous reactor at pseudosteady state was considered, in which 2-butanol was produced at a rate of $2 \mathrm{~g} /(\mathrm{L} \mathrm{h}) . F_{\mathrm{CO}_{2} \text {,in }}=$ $0.54 \mathrm{~mol} / \mathrm{h}$ represents the base case, in which the stoichiometric microbial $\mathrm{CO}_{2}$ production was considered. The results are shown in Figure 3.

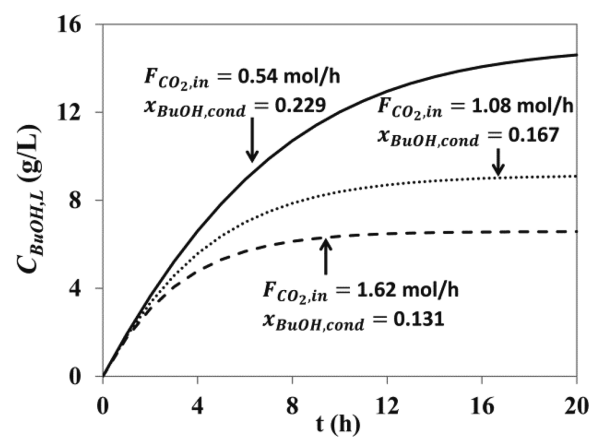

Figure 3. Predicted 2-butanol concentration profiles in the reactor during vacuum stripping at various values of $F_{\mathrm{CO}_{2}, \mathrm{in}} ; x_{\mathrm{BuOH}, \text { cond }}$ values assume full recovery from the vapor. $T=30{ }^{\circ} \mathrm{C} ; P=5.5 \mathrm{kPa}$.

The stripping rate of 2-butanol increased with the magnitude of $F_{\text {out }}$ and the concentration of 2-butanol in the reactor was kept below inhibiting levels without the requirement of additional stripping gas. However, decreasing $C_{\mathrm{BuOH}, \mathrm{L}}$ led to subsequent lower values of $y_{\mathrm{BuOH}}$. Since $C_{\mathrm{wat}, \mathrm{L}}$ was comparatively unaffected, the stripping selectivity for 2-butanol declined, i.e., increasing $F_{\text {out }}$ decreased $x_{\mathrm{BuOH}, \text { cond. }}$ Considering the base case, the composition of the stripped vapor would contain roughly $y_{\mathrm{BuOH}}=0.077, y_{\text {wat }}=0.769$, and $y_{\mathrm{CO}_{2}}=0.154$. The resulting condensate, containing nearly 23 wt \% 2-butanol, is 23 -fold more concentrated than the hydrolysate and would facilitate phase separation by decantation. However, this composition is still below the azeotropic composition (ca. 68 wt \%), anticipating high costs for product purification by distillation.

3.2. Selective Recovery of 2-Butanol by Adsorption. As discussed in the previous section, the stripped fermentation vapor is expected to comprise mostly water, 2-butanol, and $\mathrm{CO}_{2}$. Therefore, it is convenient to find an adsorbent that can selectively separate the alcohol from the vapor, such that the resulting adsorbate contains 2-butanol beyond its azeotropic composition. The isotherms obtained for the adsorption of 2butanol, water, and $\mathrm{CO}_{2}$ onto four potential adsorbents are 
depicted in Figure 4A-C, respectively. For 2-butanol and water, the equilibrium capacity is presented up to the saturated
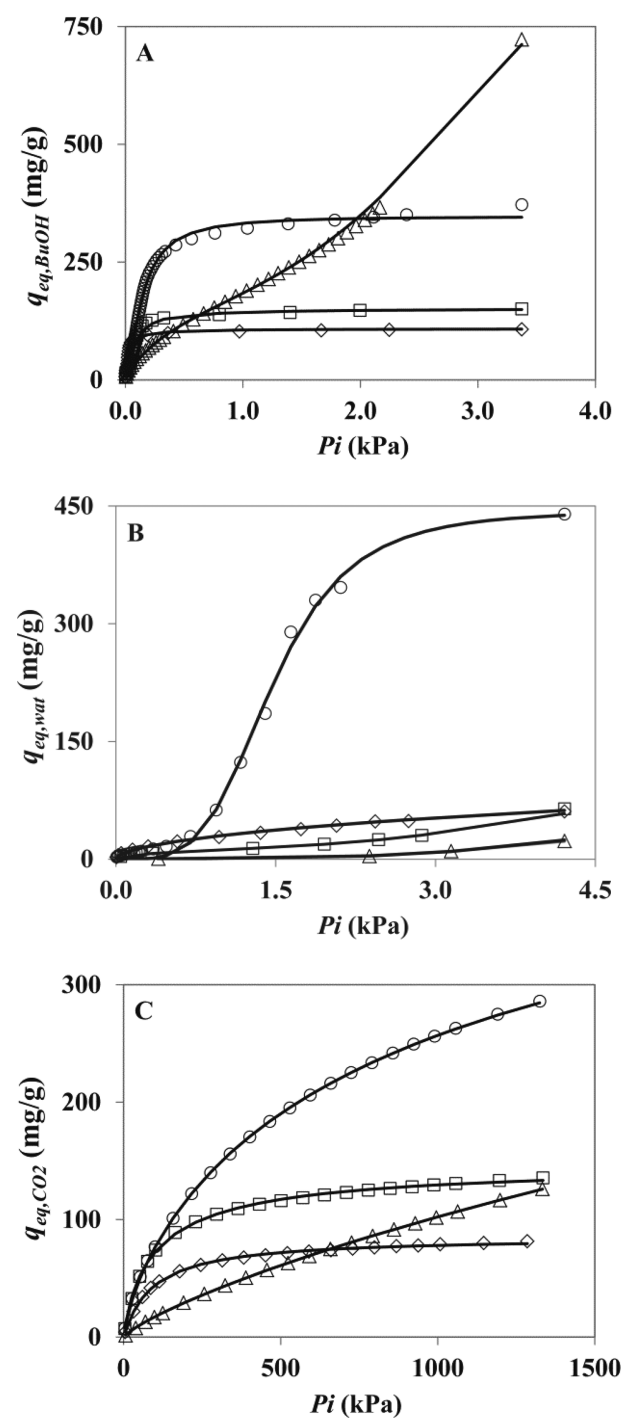

Figure 4. Adsorption isotherms of (A) 2-butanol; (B) water; and (C) $\mathrm{CO}_{2}$ onto different adsorbents. Markers represent the experimental data, and lines represent the isotherm model predictions (best fit). $T$ $=30{ }^{\circ} \mathrm{C} . \square-$ zeolite powder; $\diamond-$ silicalite pellets; $\bigcirc-$ activated carbon; $\triangle-$ resin.

vapor pressure at $30{ }^{\circ} \mathrm{C}$, using the values determined under solvent-vapor-saturated atmosphere. The lines represent the predictions by the isotherm model depicting the lowest $\delta$ for each case study, and the fitted parameters are presented in Table 3.

The resin revealed the highest adsorption capacity for 2butanol in vapor-saturated atmosphere $(723 \pm 5 \mathrm{mg} / \mathrm{g})$ and, given its hydrophobicity, the lowest adsorption capacity for water. The latter cannot hold direct comparison with that reported by Delgado et al. ${ }^{29}$ (Table 1 ), since these authors in their study did not make a distinction between the liquid phase filling the voids and the adsorbed phase. Despite these results, Figure 4 shows that the resin has the lowest affinity for the alcohol at low partial pressures. This suggests that large amounts of adsorbent are required for 2-butanol recovery from dilute vapor, leading to costly product recovery by adsorption. The clear multilayered adsorption behavior at high partial pressures suggests that capillary condensation might occur, promoting van der Waals interactions between the vapor molecules inside the pores of the resin. Therefore, the BET model provided a good fit for the resulting $S$-shaped isotherm. The adsorption of 2-butanol onto the other materials was accurately described by Langmuir-type isotherms. The maximum loadings observed for 2-butanol adsorption onto zeolite powder $(153 \mathrm{mg} / \mathrm{g})$ and silicalite pellets $(109 \mathrm{mg} / \mathrm{g}$ ) are comparable to those reported for 1-butanol adsorption onto high $\mathrm{Si} / \mathrm{Al}$ ratio materials ${ }^{25,31,62}$ (recall Table 1). The $q_{\text {max,BuOH }}$ value achieved in zeolite, $40 \%$ higher than that of silicalite, is probably due to its larger pore volume. ${ }^{25}$ The values of $b_{\mathrm{BuOH}}$ observed in the present work are much lower than those reported by Farzaneh ${ }^{31}$ for the adsorption of 1butanol onto silicalite- 1 at $35{ }^{\circ} \mathrm{C}$. This shows that the adsorbent affinity for 1-butanol is higher than for the less organophilic 2-butanol. Activated carbon depicted a slightly higher $q_{\text {max,BuOH }}$ value than that observed by Abdehagh $^{27}$ regarding 1-butanol. This is probably due to the fact that the authors tested dilute aqueous solutions, in which the alcohol loading is strongly affected by the competitive adsorption of water. The high $q_{\text {max,wat }}$ value observed for the activated carbon, similar to what is reported in the literature, ${ }^{38}$ also suggests the low selectivity of this material.

Typical S-shaped isotherms were observed for the adsorption of water vapor onto activated carbon, zeolite, and the resin (Figure 4): The low-pressure region of the isotherm revealed a low affinity for water, but at higher partial pressures, water adsorption was enhanced, due to the formation of hydrogen bonds and water clusters. ${ }^{32}$ While severe competitive adsorption is anticipated when using the activated carbon or the resin, this effect is mitigated regarding the zeolite and the silicalite, since the affinity for 2-butanol at lower pressures is comparatively high. The high value of $\delta$ observed for water adsorption onto resin relates to the small sample size, while for activated carbon it relates to the fitting errors in the lowpressure region.

The measured isotherms for $\mathrm{CO}_{2}$ (Figure 4) were successfully fitted using the Sips isotherm, suggesting heterogeneous adsorption onto the materials tested. Although the $q_{\text {max,C }}$ value for zeolite powder is within the range reported in the literature ${ }^{35,63}(124-198 \mathrm{mg} / \mathrm{g})$, it is significantly higher than that reported for activated carbon, ${ }^{37}$ possibly due to the different materials and operational conditions used. The equilibrium capacities observed for $\mathrm{CO}_{2}$ at low partial pressures are almost negligible, particularly for the resin and the silicalite. Overall, less than $8 \mathrm{mg} \mathrm{CO} / \mathrm{g}$ were adsorbed onto the materials at $5.5 \mathrm{kPa}$. Although at room pressure $\mathrm{CO}_{2}$ adsorption becomes more significant, the affinities for the gas are much lower than those observed for 2-butanol or water. This indicates that competitive adsorption of $\mathrm{CO}_{2}$ does not play an important role when predicting multicomponent adsorption at the considered vacuum pressures.

Given the diverse adsorption profiles obtained, choosing an adsorbent for the selective recovery of 2-butanol from the fermentation vapor is not straightforward: It is clear that the affinity for 2-butanol at lower partial pressures is of major importance. As an attempt to better understand competitive adsorption, the multicomponent Sips isotherm has been used, considering the vapor composition of the base case study, depicted in Figure 3. Regarding the adsorption of 2-butanol onto the resin and the adsorption of water onto the zeolite, better described by the BET isotherm, the estimated values for 
Table 3. Fitted Parameters for the Adsorption of 2-Butanol, Water, and $\mathrm{CO}_{2}$ onto Different Adsorbents at $\mathrm{T}=30^{\circ} \mathrm{C}$

\begin{tabular}{|c|c|c|c|c|}
\hline \multirow[b]{3}{*}{ best fit model } & zeolite powder & \multirow{2}{*}{$\frac{\text { silicalite pellets }}{\text { 2-butanol }}$} & \multirow[t]{2}{*}{ activated carbon } & \multirow[t]{2}{*}{ resin } \\
\hline & & & & \\
\hline & Langmuir & Langmuir & Sips & BET \\
\hline$q_{\max , i}(\mathrm{mg} / \mathrm{g})$ & $153 \pm 6$ & $109 \pm 9$ & $350 \pm 3$ & $160 \pm 5$ \\
\hline$b_{i}(1 / \mathrm{kPa})$ & $11 \pm 1$ & $41 \pm 2$ & $6.9 \pm 0.1$ & $10.1 \pm 0.2$ \\
\hline$a / \alpha(-)$ & n.a. ${ }^{a}$ & n.a. & $0.64 \pm 0.02$ & $8.0 \pm 0.7$ \\
\hline$\delta(\%)$ & 14.7 & 9.8 & 8.9 & 8.4 \\
\hline$R^{2}(-)$ & 0.965 & 0.973 & 0.994 & 0.997 \\
\hline \multicolumn{5}{|c|}{ water } \\
\hline best fit model & BET & Sips & Sips & Langmuir \\
\hline$q_{\max , i}(\mathrm{mg} / \mathrm{g})$ & $11 \pm 2$ & $992 \pm 445$ & $445 \pm 284$ & $3432 \pm 3350$ \\
\hline$b_{i}(1 / \mathrm{kPa})$ & $19 \pm 2$ & $(14 \pm 1) \times 10^{-4}$ & $0.7 \pm 0.4$ & $(1.2 \pm 1.0) \times 10^{-3}$ \\
\hline$a / \alpha(-)$ & $10.0 \pm 0.7$ & $1.9 \pm 0.3$ & $0.2 \pm 0.2$ & n.a. \\
\hline$\delta(\%)$ & 7.3 & 6.4 & 64 & 98 \\
\hline$R^{2}(-)$ & 0.999 & 0.996 & 0.996 & 0.793 \\
\hline \multicolumn{5}{|c|}{$\mathrm{CO}_{2}$} \\
\hline best fit model & Sips & Langmuir & Sips & Sips \\
\hline $\begin{array}{l}q_{\max , i}(\mathrm{mg} / \mathrm{g}) \\
b_{i}(1 / \mathrm{kPa})\end{array}$ & $\begin{array}{l}149 \pm 2 \\
(189 \pm 7) \times 10^{-4}\end{array}$ & $\begin{array}{l}85.3 \pm 0.5 \\
(107 \pm 3) \times 10^{-4}\end{array}$ & $\begin{array}{l}531 \pm 4 \\
(9.1 \pm 0.2) \times 10^{-4}\end{array}$ & $\begin{array}{l}1150 \pm 156 \\
(5.5 \pm 1.2) \times 10^{-5}\end{array}$ \\
\hline$a / \alpha(-)$ & $1.18 \pm 0.03$ & n.a. & $1.3 \pm 0.3$ & $1.24 \pm 0.01$ \\
\hline$\delta(\%)$ & 1.7 & 1.3 & 0.6 & 2.3 \\
\hline$R^{2}(-)$ & 0.999 & 0.998 & 1.000 & 1.000 \\
\hline
\end{tabular}

Table 4. Estimated Equilibrium Adsorption of 2-Butanol, Water, and $\mathrm{CO}_{2}$ from Stripped Fermentation Vapor onto Different Adsorbents at $T=30^{\circ} \mathrm{C}$ and $P=5.5 \mathrm{kPa}$

\begin{tabular}{|c|c|c|c|c|}
\hline & \multicolumn{4}{|c|}{$q_{\mathrm{eq}, i}(\mathrm{mg} / \mathrm{g})$} \\
\hline & zeolite powder & silicalite pellets & activated carbon & resin \\
\hline 2-butanol & $125.6 \pm 12.4$ & $103.0 \pm 9.9$ & $164.9 \pm 5.8$ & $76.4 \pm 31.0$ \\
\hline water & $8.9 \pm 3.9$ & $0.3 \pm 0.1$ & $222.3 \pm 190.4$ & $17.3 \pm 22.2$ \\
\hline $\mathrm{CO}_{2}$ & $0.40 \pm 0.02$ & $0.042 \pm 0.001$ & $0.06 \pm 0.01$ & $0.14 \pm 0.04$ \\
\hline$\varepsilon_{\mathrm{BuOH}}(-)$ & $0.9 \pm 0.4$ & $1.0 \pm 0.5$ & $0.4 \pm 0.4$ & $0.8 \pm 1.1$ \\
\hline
\end{tabular}

the Langmuir model parameters have been used $\left(q_{\mathrm{max}, \mathrm{BuOH}}=\right.$ $110.6 \mathrm{~g} / \mathrm{g}, b_{\mathrm{BuOH}}=1.6 \times 10^{-3}(1 / \mathrm{kPa}), \delta=29 \%$ and $q_{\mathrm{max}, \mathrm{H}_{2} \mathrm{O}}=$ $1534.8 \mathrm{~g} / \mathrm{g}, b_{\mathrm{H}_{2} \mathrm{O}}=7.8 \times 10^{-6}(1 / \mathrm{kPa}), \delta=31 \%$, respectively). On the basis of estimated values of $q_{\mathrm{eq}, i}(\mathrm{mg} / \mathrm{g})$, the adsorbent selectivity for 2-butanol has been determined as $\varepsilon_{\mathrm{BuOH}}=$ $q_{\mathrm{eq}, \mathrm{BuOH}} / \sum q_{\mathrm{eq}, i^{\circ}}$. The results are depicted in Table 4 .

Although adsorbents such as activated carbon are often pointed out as the most promising option for the selective recovery of biobutanol, ${ }^{27,64,65}$ the present study suggests that silicalite materials, particularly HiSiv3000, offer higher selectivity over water at lower alcohol partial pressures. However, the adsorbent selectivity for 2-butanol is affected by great errors, mostly due to the impracticability of describing the adsorption behavior using a single model. It is important to note that the prediction of multicomponent adsorption is challenging using simple adsorption models for hydrogen bonding systems. ${ }^{66}$ Therefore, it is strongly recommended that the multicomponent equilibrium data presented in this work are further validated using actual stripped fermentation vapor. Silicalite materials are known to be more selective for 1butanol when compared to other solvents such as ethanol or acetone, since more organophilic components are adsorbed preferentially. ${ }^{62,67}$ Bearing in mind the $\log P$ values of the hydrolysate compounds that might be vacuum stripped, considerably lower than that of 2-butanol, the alcohol is expected to be adsorbed favorably.

3.3. Prospects for the Vacuum Stripping of Fermentation Broth Integrated with Adsorption. The feasibility of integrated vacuum stripping and adsorption of 2-butanol using silicalite HiSiv3000 was further investigated using Adsim. The column feed matched the base case off-gas composition (recall Figure 3), as described in section 3.1.

Although the first option was to use the vapor stream directly from the bioreactor $\left(T=33{ }^{\circ} \mathrm{C}, P=5.5 \mathrm{kPa}\right)$, it became clear that the maximum attainable vapor velocity $(0.05$ $\mathrm{m} / \mathrm{s}$ ) was limited by the pressure drop in the column. This affected significantly the bed volume $\left(1067 \mathrm{~m}^{3}\right)$ and crosssectional area (ca. $4500 \mathrm{~m}^{2}$ ), compromising the equipment sizing. By compressing the vapor feed to $10.0 \mathrm{kPa}$, the vapor velocity increased to $0.10 \mathrm{~m} / \mathrm{s}$. As a result, the required mass of adsorbent decreased by 2.4 -fold, and the adsorption productivity increased from $0.011 \mathrm{~kg}_{\mathrm{BuOH}} /\left(\mathrm{kg}_{\mathrm{ads}} \mathrm{h}\right)$ to 0.024 $\mathrm{kg}_{\mathrm{BuOH}} /\left(\mathrm{kg}_{\mathrm{ads}} \mathrm{h}\right)$. Further vapor compression to $20.0 \mathrm{kPa}$ reduced the 2 -butanol fraction in the vapor by $44 \%$, anticipating significant costs due to product recovery from the resulting dilute condensate. Therefore, a preliminary vapor compression step, up to $10.0 \mathrm{kPa}$, has been considered. The effect of the feed pressure on 2-butanol breakthrough curve is depicted in Figure 5, along with the 2-butanol content (wt \%) 


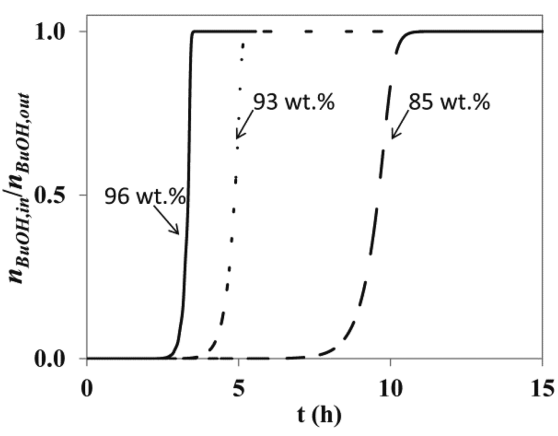

Figure 5. Breakthrough curves of 2-butanol using different feed pressures: $P=5.5 \mathrm{kPa}$ (dashed line), $P=10.0 \mathrm{kPa}$ (dotted line), and $P=20.0 \mathrm{kPa}$ (solid line).

in the resulting adsorbate. Taking into account the recovery target of 99 wt \% of the stripped 2-butanol, the adsorption step must be stopped when this specification is reached, i.e., around $4.5 \mathrm{~h}$ considering the adsorption pressure of $10.0 \mathrm{kPa}$. At this point, the adsorbate within the column contained roughly 93 wt \% 2-butanol, which is substantially higher than the azeotrope composition. The prospects for the adsorptionbased recovery of 2-butanol produced by vacuum fermentation have been discussed in Pereira et al., ${ }^{7}$ on the basis of preliminary data. The overall energy duty was estimated to be $21.9 \mathrm{MJ} / \mathrm{kg}$ with highly pure 2-butanol (99 wt \%) as the final product. Although the overall energy duty of the integrated configuration is expected to be high using the current adsorption data, a convenient stream of 2-butanol beyond azeotropic composition can be obtained.

\section{CONCLUSIONS}

Aiming at the selective recovery of biobased 2-butanol, the feasibility of an integrated process combining in situ vacuum stripping and adsorption has been assessed. As a result of vacuum stripping, the concentration of 2-butanol in the bioreactor can be kept below inhibiting levels without the requirement of additional stripping gas. However, the presence of hydrolysate impurities hindered the efficiency of 2-butanol recovery by condensation, which decreased from 96 wt \% in model solutions, to $40 \mathrm{wt} \%$ using hydrolysate. While the content of 2-butanol in the condensate was ca. 23-fold higher than in the bioreactor, this was still below the azeotropic composition of 2-butanol/water systems.

Integrating vacuum stripping with vapor adsorption using silicalite HiSiv3000 proved advantageous to achieve 2-butanol contents beyond the azeotropic composition. On the basis of the results provided by the mathematical simulation, adsorbates containing up to 93 wt \% 2-butanol can be obtained after desorption. However, it is strongly recommended that the data presented in this work are further validated using actual fermentation broth and the resulting stripped fermentation vapor.

\section{ASSOCIATED CONTENT}

\section{S Supporting Information}

The Supporting Information is available free of charge on the ACS Publications website at DOI: 10.1021/acs.iecr.8b03043.

Equilibrium adsorption for vapor phase single-component $\left(T=30^{\circ} \mathrm{C}\right)(\mathrm{PDF})$

\section{AUTHOR INFORMATION}

Corresponding Author

*E-mail: A.J.J.Strathof@tudelft.nl. Telephone: $+31152782330$

ORCID

Joana P. C. Pereira: 0000-0002-2352-5243

Freek Kapteijn: 0000-0003-0575-7953

Adrie J. J. Straathof: 0000-0003-2877-4756

Funding

This project is financially supported by The Netherlands Organization for Scientific Research (NWO) within the framework of Technology Area TA-Biomass (grant number: TA-Biomass 053.24.105).

\section{Notes}

The authors declare no competing financial interest.

\section{ACKNOWLEDGMENTS}

We would like to acknowledge Willy Rook, Yi Song, Max Zomerdijk, Dirk Geerts, and Stef van Hateren for their analytical support. We would also like to thank Chris Jugters (UOP Products, Belgium BVBA) for providing the HiSiv 3000, Chemviron Carbon (Belgium) for providing the activated carbon F-400, Resindion S.R.L. (Italy) for providing the Sepabeads SP207, and DSM (Delft, The Netherlands) for providing the corn stover hydrolysate.

\section{NOMENCLATURE}

$a=[-]$ Index of heterogeneity in Sips equation

$A=\left[\mathrm{m}^{2}\right]$ Solid interface area

$b=[1 / \mathrm{bar}]$ Affinity constant for adsorption

$C=[\mathrm{mol} / \mathrm{L}]$ Concentration

$\mathrm{C}^{*}=[\mathrm{mol} / \mathrm{L}]$ Concentration at the liquid interface

$F=[\mathrm{mol} / \mathrm{h}]$ Mole flow rate

$H=[\mathrm{L} \mathrm{bar} / \mathrm{mol}]$ Henry's coefficient

$k_{\mathrm{L}} a=[1 / \mathrm{h}]$ Volume-specific mass transfer coefficient

$K_{i}=[\mathrm{bar} / \mathrm{bar}]$ Distribution coefficient

$M_{\mathrm{w}}=[\mathrm{g} / \mathrm{mol}]$ Molecular mass

$n=[-]$ Number of observations

$n^{*}=[\mathrm{mol}]$ Number of moles at the liquid interface

$P=[$ bar $]$ Pressure

$P^{\text {Sat }}=[$ bar $]$ Saturation pressure

$r=[\mathrm{mol} /(\mathrm{L} \mathrm{h})]$ Rate of formation

$R=[\mathrm{L} \mathrm{bar} /(\mathrm{K}$ mol $)]$ Ideal gas constant

$S=[-]$ Selectivity

$q=[\mathrm{mg} / \mathrm{g}]$ Adsorption capacity

$t=[\mathrm{h}]$ Time

$T=[\mathrm{K}]$ Temperature

$V=[\mathrm{L}]$ Volume

$x=[-]$ Mole fraction in the liquid phase

$y=[-]$ Mole fraction in the vapor phase

\section{Greek Symbols}

$\alpha=[-]$ Average number of adsorption layers in BET isotherm

$\delta=[\%]$ Average relative error

$\gamma=[-]$ Activity coefficient

$\varepsilon=[-]$ Adsorbent selectivity

$\theta=[\mathrm{mol} / \mathrm{h}]$ Transfer rate from liquid to gas phase

$\rho=[\mathrm{g} / \mathrm{L}]$ Density

\section{Subscripts}

broth $=$ Fermentation broth

$\mathrm{BuOH}=2$-Butanol 


$$
\begin{aligned}
& C=\text { Carbon dioxide } \\
& \text { cond = Condensate } \\
& \text { eq = Equilibrium } \\
& \text { exp = Experimental } \\
& \mathrm{G}=\text { Vapor phase } \\
& i=\text { Component } i \\
& \text { in }=\text { In } \\
& j=\text { Component } j \\
& \mathrm{~L}=\text { Liquid phase } \\
& \text { max = Maximum } \\
& \text { mix = Mixture } \\
& \text { mod = Predicted by model } \\
& \text { out }=\text { Out } \\
& \text { strip = Stripped } \\
& \text { tot }=\text { Total } \\
& \text { wat }=\text { Water }
\end{aligned}
$$

\section{REFERENCES}

(1) Straathof, A. J. J. Transformation of Biomass into Commodity Chemicals Using Enzymes or Cells. Chem. Rev. 2014, 114, 18711908.

(2) Pereira, J. P. C.; van der Wielen, L. A. M.; Straathof, A. J. J. Perspectives for the Microbial Production of Methyl Propionate Integrated with Product Recovery. Bioresour. Technol. 2018, 256, 187-194.

(3) Bramucci, M. G.; Flint, D.; Miller, E. S.; Nagarajan, V.; Sedkova, N.; Singh, M.; Van Dyk, T. K. Method for the Production of 2Butanol. U.S. Patent 8426174B2, 2013.

(4) Burk, M. J.; Pharkya, P.; Burgard, A. P. Microorganisms for the Production of Methyl Ethyl Ketone and 2-Butanol. U.S. Patent 20100184173A1, 2010.

(5) Ghiaci, P.; Norbeck, J.; Larsson, C. 2-Butanol and Butanone Production in Saccharomyces Cerevisiae through Combination of a B12 Dependent Dehydratase and a Secondary Alcohol Dehydrogenase Using a Tev-Based Expression System. PLoS One 2014, 9, e102774.

(6) Chen, Z.; Wu, Y.; Huang, J.; Liu, D. Metabolic Engineering of Klebsiella Pneumoniae for the De Novo Production of 2-Butanol as a Potential Biofuel. Bioresour. Technol. 2015, 197, 260-265.

(7) Pereira, J. P. C.; Lopez-Gomez, G.; Reyes, N. G.; van der Wielen, L. A. M.; Straathof, A. J. J. Prospects and Challenges for the Recovery of 2-Butanol Produced by Vacuum Fermentation - a TechnoEconomic Analysis. Biotechnol. J. 2017, 12, 1600657.

(8) Speranza, G.; Corti, S.; Fontana, G.; Manitto, P.; Galli, A.; Scarpellini, M.; Chialva, F. Conversion of Meso-2,3-Butanediol into 2Butanol by Lactobacilli. Stereochemical and Enzymatic Aspects. J. Agric. Food Chem. 1997, 45, 3476-3480.

(9) Van Dien, S. From the First Drop to the First Truckload: Commercialization of Microbial Processes for Renewable Chemicals. Curr. Opin. Biotechnol. 2013, 24, 1061-1068.

(10) Park, S. J.; Lee, S. H.; Lee, S. Y.; Lee, E. J. Mutants Having Capability to Produce 1,4-Butanediol and Method for Preparing 1,4Butanediol. U.S. Patent 9096860B2, 2009.

(11) Pereira, J. P. C.; Verheijen, P. J. T.; Straathof, A. J. J. Growth Inhibition of S. Cerevisiae, B. Subtilis, and E. Coli by Lignocellulosic and Fermentation Products. Appl. Microbiol. Biotechnol. 2016, 100, 9069-9080.

(12) Mukhopadhyay, A. Tolerance Engineering in Bacteria for the Production of Advanced Biofuels and Chemicals. Trends Microbiol. 2015, 23, 498-508.

(13) Van Hecke, W.; Kaur, G.; De Wever, H. Advances in in-Situ Product Recovery (ISPR) in Whole Cell Biotechnology During the Last Decade. Biotechnol. Adv. 2014, 32, 1245-1255.

(14) Xue, C.; Zhao, J.-B.; Chen, L.-J.; Bai, F.-W.; Yang, S.-T.; Sun, J.X. Integrated Butanol Recovery for an Advanced Biofuel: Current State and Prospects. Appl. Microbiol. Biotechnol. 2014, 98, 3463-3474.

(15) Outram, V.; Lalander, C.-A.; Lee, J. G. M.; Davis, E. T.; Harvey, A. P. A Comparison of the Energy Use of in Situ Product Recovery
Techniques for the Acetone Butanol Ethanol Fermentation. Bioresour. Technol. 2016, 220, 590-600.

(16) Nguyen, V. D.; Auresenia, J.; Kosuge, H.; Tan, R. R.; Brondial, Y. Vacuum Fermentation Integrated with Separation Process for Ethanol Production. Biochem. Eng. J. 2011, 55, 208-214.

(17) Mariano, A. P.; Qureshi, N.; Filho, R. M.; Ezeji, T. C. Assessment of in Situ Butanol Recovery by Vacuum During Acetone Butanol Ethanol (ABE) Fermentation. J. Chem. Technol. Biotechnol. 2012, 87, 334-340.

(18) Vane, L. M. Separation Technologies for the Recovery and Dehydration of Alcohols from Fermentation Broths. Biofuels, Bioprod. Biorefin. 2008, 2, 553-588.

(19) Díaz, V. H. G.; Tost, G. O. Butanol Production from Lignocellulose by Simultaneous Fermentation, Saccharification, and Pervaporation or Vacuum Evaporation. Bioresour. Technol. 2016, 218, 174-182.

(20) Patraşcu, I.; Bîldea, C. S.; Kiss, A. A. Eco-Efficient Butanol Separation in the ABE Fermentation Process. Sep. Purif. Technol. 2017, 177, 49-61.

(21) Qureshi, N.; Hughes, S.; Maddox, I. S.; Cotta, M. A. EnergyEfficient Recovery of Butanol from Model Solutions and Fermentation Broth by Adsorption. Bioprocess Biosyst. Eng. 2005, 27, 215-222.

(22) Xue, C.; Liu, F.; Xu, M.; Tang, I. C.; Zhao, J.; Bai, F.; Yang, S.T. Butanol Production in Acetone-Butanol-Ethanol Fermentation with in Situ Product Recovery by Adsorption. Bioresour. Technol. 2016, 219, 158-168.

(23) Taqvi, S. M.; Appel, W. S.; LeVan, M. D. Coadsorption of Organic Compounds and Water Vapor on BPL Activated Carbon. 4. Methanol, Ethanol, Propanol, Butanol, and Modeling. Ind. Eng. Chem. Res. 1999, 38, 240-250.

(24) Águeda, V. I.; Delgado, J. A.; Uguina, M. A.; Sotelo, J. L.; García, A. Column Dynamics of an Adsorption-Drying-Desorption Process for Butanol Recovery from Aqueous Solutions with Silicalite Pellets. Sep. Purif. Technol. 2013, 104, 307-321.

(25) Oudshoorn, A.; van der Wielen, L. A. M.; Straathof, A. J. J. Adsorption Equilibria of Bio-Based Butanol Solutions Using Zeolite. Biochem. Eng. J. 2009, 48, 99-103.

(26) Oudshoorn, A.; van der Wielen, L. A. M.; Straathof, A. J. J. Desorption of Butanol from Zeolite Material. Biochem. Eng. J. 2012, 67, 167-172.

(27) Abdehagh, N.; Tezel, F. H.; Thibault, J. Adsorbent Screening for Biobutanol Separation by Adsorption: Kinetics, Isotherms and Competitive Effect of Other Compounds. Adsorption 2013, 19, $1263-1272$

(28) Pyrgakis, K. A.; de Vrije, T.; Budde, M. A. W.; Kyriakou, K.; López-Contreras, A. M.; Kokossis, A. C. A Process Integration Approach for the Production of Biological Iso-Propanol, Butanol and Ethanol Using Gas Stripping and Adsorption as Recovery Methods. Biochem. Eng. J. 2016, 116, 176-194.

(29) Delgado, J. A.; Águeda, V. I.; Uguina, M. A.; Sotelo, J. L.; García, A.; Brea, P.; García-Sanz, A. Separation of Ethanol-Water Liquid Mixtures by Adsorption on a Polymeric Resin Sepabeads 207®. Chem. Eng. J. 2013, 220, 89-97.

(30) Delgado, J. A.; Uguina, M. A.; Sotelo, J. L.; Águeda, V. I.; Gómez, P.; Hernández, V. Modeling the Regeneration of a Polymeric Resin Column Saturated with Ethanol by Air Purge and External Heating. Sep. Sci. Technol. 2011, 46, 1740-1749.

(31) Farzaneh, A.; Zhou, M.; Potapova, E.; Bacsik, Z.; Ohlin, L.; Holmgren, A.; Hedlund, J.; Grahn, M. Adsorption of Water and Butanol in Silicalite-1 Film Studied with in Situ Attenuated Total Reflectance-Fourier Transform Infrared Spectroscopy. Langmuir 2015, 31, 4887-4894.

(32) Jentys, A.; Warecka, G.; Derewinski, M.; Lercher, J. A. Adsorption of Water on ZSM 5 Zeolites. J. Phys. Chem. 1989, 93, 4837-4843.

(33) Gorbach, A.; Stegmaier, M.; Eigenberger, G. Measurement and Modeling of Water Vapor Adsorption on Zeolite $4 a-$ Equilibria and Kinetics. Adsorption 2004, 10, 29-46. 
(34) Nastaj, J.; Chybowska, M. Adsorption Equilibria of Butan-1-Ol, Toluene and Water Vapour onto Sorbonorit 4 Activated Carbon and the Co-Adsorption of Organic Compounds and Water Vapour onto SKT Activated Carbon. Adsorpt. Sci. Technol. 2006, 24, 283-300.

(35) Lopes, F. V. S.; Grande, C. A.; Ribeiro, A. M.; Loureiro, J. M.; Evaggelos, O.; Nikolakis, V.; Rodrigues, A. E. Adsorption of H2, CO2, $\mathrm{CH} 4, \mathrm{CO}, \mathrm{N} 2$ and $\mathrm{H} 2 \mathrm{O}$ in Activated Carbon and Zeolite for Hydrogen Production. Sep. Sci. Technol. 2009, 44, 1045-1073.

(36) Löser, C.; Schröder, A.; Deponte, S.; Bley, T. Balancing the Ethanol Formation in Continuous Bioreactors with Ethanol Stripping. Eng. Life Sci. 2005, 5, 325-332.

(37) Nastaj, J.; Aleksandrzak, T. Adsorption Isotherms of Water, Propan-2-ol, and Methylbenzene Vapors on Grade 03 Silica Gel, Sorbonorit 4 Activated Carbon, and HiSiv 3000 Zeolite. J. Chem. Eng. Data 2013, 58, 2629-2641.

(38) Rudisill, E. N.; Hacskaylo, J. J.; LeVan, M. D. Coadsorption of Hydrocarbons and Water on BPL Activated Carbon. Ind. Eng. Chem. Res. 1992, 31, 1122-1130.

(39) Urit, T.; Löser, C.; Wunderlich, M.; Bley, T. Formation of Ethyl Acetate by Kluyveromyces Marxianus on Whey: Studies of the Ester Stripping. Bioprocess Biosyst. Eng. 2011, 34, 547-559.

(40) Contreras, E. M. Carbon Dioxide Stripping in Bubbled Columns. Ind. Eng. Chem. Res. 2007, 46, 6332-6337.

(41) Millero, F. J.; Pierrot, D.; Lee, K.; Wanninkhof, R.; Feely, R.; Sabine, C. L.; Key, R. M.; Takahashi, T. Dissociation Constants for Carbonic Acid Determined from Field Measurements. Deep Sea Res., Part I 2002, 49, 1705-1723.

(42) Senanayake, P. C.; Gee, N.; Freeman, G. R. Viscosity and Density of Isomeric Butanol/Water Mixtures as Functions of Composition and Temperature. Can. J. Chem. 1987, 65, 2441-2446.

(43) Hou, W.; Li, L.; Bao, J. Oxygen Transfer in High Solids Loading and Highly Viscous Lignocellulose Hydrolysates. ACS Sustainable Chem. Eng. 2017, 5, 11395-11402.

(44) Truong, K. N.; Blackburn, J. W. The Stripping of Organic Chemicals in Biological Treatment Processes. Environ. Prog. 1984, 3, $143-152$.

(45) Gmehling, J.; Wittig, R.; Lohmann, J.; Joh, R. A Modified Unifac (Dortmund) Model. 4. Revision and Extension. Ind. Eng. Chem. Res. 2002, 41, 1678-1688.

(46) Poling, B.; Prausnitz, J.; Connell, J. O. The Properties of Gases and Liquids; McGraw-Hill Education, 2000.

(47) Green, D.; Perry, R. Perry's Chemical Engineers' Handbook, 8th ed., McGraw-Hill Education, 2007.

(48) Foo, K. Y.; Hameed, B. H. Insights into the Modeling of Adsorption Isotherm Systems. Chem. Eng. J. 2010, 156, 2-10.

(49) Langmuir, I. The Constitution and Fundamental Properties of Solids and Liquids. Part 1. Solids. J. Am. Chem. Soc. 1916, 38, 22212295.

(50) Sips, R. Combined Form of Langmuir and Freundlich Equations. J. Chem. Phys. 1948, 16, 490-495.

(51) Brunauer, S.; Emmett, P. H.; Teller, E. Adsorption of Gases in Multimolecular Layers. J. Am. Chem. Soc. 1938, 60, 309-319.

(52) Freundlich, H. M. F. Over the Adsorption in Solution. J. Phys. Chem. 1906, 57, 385-471.

(53) Do, D. D. Adsorption Analysis: Equilibria and Kinetics; Imperial College Press: London, 1998.

(54) Ergun, S.; Orning, A. A. Fluid Flow through Randomly Packed Columns and Fluidized Beds. Ind. Eng. Chem. 1949, 41, 1179-1184.

(55) Bonjour, J.; Chalfen, J.-B.; Meunier, F. Temperature Swing Adsorption Process with Indirect Cooling and Heating. Ind. Eng. Chem. Res. 2002, 41, 5802-5811.

(56) Joss, L.; Gazzani, M.; Hefti, M.; Marx, D.; Mazzotti, M. Temperature Swing Adsorption for the Recovery of the Heavy Component: An Equilibrium-Based Shortcut Model. Ind. Eng. Chem. Res. 2015, 54, 3027-3038.

(57) Sircar, S.; Hufton, J. R. Why Does the Linear Driving Force Model for Adsorption Kinetics Work? Adsorption 2000, 6, 137-147.

(58) de Vrije, T.; Budde, M.; van der Wal, H.; Claassen, P. A. M.; López-Contreras, A. M. In Situ" Removal of Isopropanol, Butanol and
Ethanol from Fermentation Broth by Gas Stripping. Bioresour. Technol. 2013, 137, 153-159.

(59) Chen, Y.; Ren, H.; Liu, D.; Zhao, T.; Shi, X.; Cheng, H.; Zhao, N.; Li, Z.; Li, B.; et al. Enhancement of N-Butanol Production by in Situ Butanol Removal Using Permeating-Heating-Gas Stripping in Acetone-Butanol-Ethanol Fermentation. Bioresour. Technol. 2014, $164,276-284$.

(60) Tan, T. C.; Gan, S. H. Vapour-Liquid Equilibrium of Water/ Ethanol/1-Butanol/Salt: Prediction and Experimental Verification. Chem. Eng. Res. Des. 2005, 83, 1361-1371.

(61) Oudshoorn, A.; Peters, M. C. F. M.; van der Wielen, L. A. M.; Straathof, A. J. J. Exploring the Potential of Recovering 1-Butanol from Aqueous Solutions by Liquid Demixing Upon Addition of Carbohydrates or Salts. J. Chem. Technol. Biotechnol. 2011, 86, 714718.

(62) Saravanan, V.; Waijers, D. A.; Ziari, M.; Noordermeer, M. A. Recovery of 1-Butanol from Aqueous Solutions Using Zeolite ZSM-5 with a High Si/Al Ratio; Suitability of a Column Process for Industrial Applications. Biochem. Eng. J. 2010, 49, 33-39.

(63) Ohlin, L.; Bazin, P.; Thibault-Starzyk, F.; Hedlund, J.; Grahn, M. Adsorption of $\mathrm{CO} 2, \mathrm{CH} 4$, and $\mathrm{H} 2 \mathrm{O}$ in Zeolite ZSM-5 Studied Using in Situ ATR-FTIR Spectroscopy. J. Phys. Chem. C 2013, 117, 16972-16982.

(64) Cao, Y.; Wang, K.; Wang, X.; Gu, Z.; Gibbons, W.; Vu, H. Butanol Vapor Adsorption Behavior on Active Carbons and Zeolite Crystal. Appl. Surf. Sci. 2015, 349, 1-7.

(65) Abdehagh, N.; Gurnani, P.; Tezel, F. H.; Thibault, J. Adsorptive Separation and Recovery of Biobutanol from ABE Model Solutions. Adsorption 2015, 21, 185-194.

(66) Krishna, R.; van Baten, J. M. Hydrogen Bonding Effects in Adsorption of Water-Alcohol Mixtures in Zeolites and the Consequences for the Characteristics of the Maxwell-Stefan Diffusivities. Langmuir 2010, 26, 10854-10867.

(67) Milestone, N. B.; Bibby, D. M. Concentration of Alcohols by Adsorption on Silicalite. J. Chem. Technol. Biotechnol. 1981, 31, 732736. 